\title{
Frequency of Raised Total Serum Ig E, Sputum Eosinophilia and Blood Eosinophil Count in Patients with Severe Persistent Asthma
}

\author{
Shanawer Qaiser, Muhammad Saqib, Talha Mahmud \\ Department of Pulmonology, Shaikh Zayed Medical Complex, Lahore
}

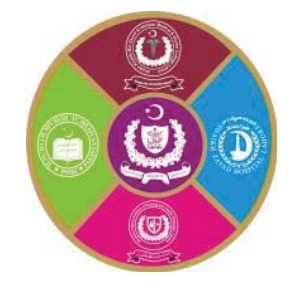

\begin{abstract}
Introduction: Asthma is a chronic inflammatory airway disorder that has several inflammatory phenotypes. Serum immunoglobulin E (IgE) and eosinophils are airway inflammation markers in asthmatic patients. In this research, we assessed the asthma severity with various inflammatory markers. Aims \& Objectives: To find the frequency of raised total serum immunoglobulin E, sputum eosinophilia, and absolute blood eosinophil count in patients with severe persistent asthma. Place and duration of study: This study was conducted in Department of Pulmonology, Shaikh Zayed FPGMI, Lahore from $1^{\text {st }}$ October 2018 to $1^{\text {st }}$ April 2019. Material \& Methods: A Cross-sectional study in which total of 125 patients were enrolled after fulfilling the inclusion criteria. Blood samples were taken with aseptic measures for total serum immunoglobulin E and absolute blood eosinophils count. Sputum was collected in the sterile jar and dispensed properly to the histopathology lab. Results: Of 125 patients, $44.8 \%$ were males, and 55.2\% were females. The mean patient's age was 49.37 years, and the mean duration of symptoms was 25.49 years. Raised serum immunoglobulin E levels were seen in $74.4 \%$ patients, sputum eosinophilia was seen in $25.6 \%$ patients, and increased peripheral eosinophil count was seen in $55.2 \%$. Age was significantly associated with sputum eosinophilia; however, no such association was seen between the other effect modifiers and inflammatory markers. Conclusion: Inflammatory markers immunoglobulin E, sputum and blood eosinophil levels were significantly raised in asthma patients. These can be used in the detection of asthma as their detection is easy, simple, and non-invasive, and they are directly linked to the inflammation.
\end{abstract}

Key words: Asthma, Serum Immunoglobulin E, Sputum Eosinophilia, Peripheral Serum Eosinophilia

\section{INTRODUCTION}
A sthma is a common illness whose prevalence has increased all over the world for many years. Worldwide, the asthma prevalence has dramatic variations, with specifically higher rates in some developed countries like Canada, the USA, Australia, UK, and New Zealand. ${ }^{1}$ In the US, the asthma prevalence has increased relentlessly from 1980 to 2011. In 2012, total lifetime asthma prevalence was $13.0 \%$, and the current asthma prevalence was $8.3 \% .^{2}$ Prevalence of bronchial asthma in Pakistan was $19.36 \% .^{3}$ Deaths due to asthma was once thought to be rare, but World Health Organization data shows 418,917 deaths due to this disease worldwide. ${ }^{4}$
Asthma is a chronic inflammatory airways disorder in which many cells and cellular elements play a part, including eosinophils, mast cells, epithelial cells, neutrophils, T lymphocytes, and macrophages.

In susceptible individuals, inflammation causes repeated episodes of coughing, breathlessness, wheezing, and chest tightness, most in the early morning or at night time. These episodes are linked with variable airflow obstruction that is often reversible either spontaneously or with treatment. The inflammation also increases associated hyper bronchial responsiveness to a variety of stimuli. ${ }^{5}$ It is now found that asthma has several inflammatory phenotypes, and Simpson has suggested dividing asthma on the basis of granulocyte component contained in sputum cells. ${ }^{6}$ Based on cytological analysis of sputum, there are four categories of asthma: (1)neutrophilic, (2)eosinophilic, (3)mixed neutrophilic and eosinophilic, (4)pauci granulocytic asthma, when no inflammatory cells are detected. ${ }^{7,89}$

Current guidelines assess asthma severity according to the degree of severity of symptoms, nighttime awakenings, use of rescue inhaler medication, asthma exacerbations, and severity of airflow 
obstruction. ${ }^{10-11} \mathrm{~A}$ recent study from India on the association of total serum immunoglobulin E, sputum, and blood eosinophilia with the severity of asthma has shown a notable association between peripheral blood eosinophil count, sputum eosinophil count, and total serum IgE with severe persistent asthma. ${ }^{12}$ Seventy-six patients were enrolled in that study in which 34 had severe persistent asthma, $100 \%$ of severe asthmatic patients had raised serum IgE level, and $19.7 \%$ had sputum eosinophilia. ${ }^{12}$

In this study, we intend to evaluate the severity of asthma with various inflammatory markers, and we will know the frequency of eosinophilic asthma in patients of severe persistent asthma. Many studies are done on this topic in the western world, but there is not much local data on this topic. This study will add to the existing body of knowledge.

\section{MATERIAL AND METHODS}

The study was a cross-sectional study and was conducted in the Department of Pulmonology, Shaikh Zayed Hospital, Post Graduate Medical Institute Lahore.

A sample size of 125 was estimated, and the sampling technique was non-probability consecutive sampling. Patients presenting to the Outdoor Department or admitted to the Pulmonology Ward of either sex having age 15 to 80 years and fulfilling the criteria of severe persistent asthma were included in our study while patients suffering from eosinophilic pneumonia, Allergic Bronchopulmonary Aspergillosis, Churg Strauss syndrome and with hematological malignancies were excluded. The informed consent was obtained from all the patients. Blood samples were taken with aseptic measures for total serum immunoglobulin E and absolute blood eosinophils count. Sputum was collected in the sterile jar and dispensed properly to the histopathology lab. Sputum eosinophilia was recorded. The confidentiality of data was assured.

\section{Statistical analysis:}

Data were analyzed using SPSS version 20.0. Quantitative variables like age and duration of symptoms were described as mean \pm standard deviation. Qualitative variables like raised serum immunoglobulin E, sputum eosinophilia, and increased absolute eosinophil count were described as frequencies and percentages. Data was stratified for age, gender, and duration of symptoms. Chisquare test was applied, taking P-value less than or equal to 0.05 as significant.

\section{RESULTS}

A total of 125 patients were recruited in the study. The mean age of the patients was 49.37 years, with a standard deviation of 12.11. The mean duration of symptoms was 25.49 years, with a standard deviation of 9.326. Among the participants, $44.8 \%$ were males, and $55.2 \%$ were females. Raised serum immunoglobulin E was present in $74.4 \%$ of the patients. Sputum eosinophilia was noticed in $25.6 \%$ of the patients, and the increased peripheral eosinophilic count was seen in $55.2 \%$ of the patients. (Table-1)

Data was stratified for age, gender, and duration of symptoms. Post-stratification, chi-square test, was applied, and it was seen that age was significantly associated with sputum eosinophilia, as indicated by a P-value of $\leq 0.05$. (Table-2) None of the other factors had any association with raised serum immunoglobulin E levels, Sputum eosinophilia, and increased peripheral eosinophilic count.

\begin{tabular}{|l|c|}
\hline \multicolumn{1}{|c|}{ Variable } & N= 125 \\
\hline Age(years) Mean \pm SD & $49.37 \pm 12.11$ \\
\hline $\begin{array}{l}\text { Sex } \\
\quad \text { Male } \\
\text { Female }\end{array}$ & $56(44.8 \%)$ \\
\hline $\begin{array}{l}\text { Duration of symptoms (years) } \\
\text { Mean } \pm \text { SD }\end{array}$ & $69(55.2 \%)$ \\
\hline $\begin{array}{l}\text { Raised serum immunoglobulin E } \\
\text { Yes } \\
\text { No }\end{array}$ & $25.49 \pm 9.32$ \\
\hline $\begin{array}{l}\text { Sputum eosinophilia } \\
\text { Yes } \\
\text { No }\end{array}$ & $93(74.4 \%)$ \\
\hline $\begin{array}{l}\text { Increased peripheral eosinophilic count } \\
\text { Yes } \\
\text { No }\end{array}$ & $32(25.6 \%)$ \\
\hline
\end{tabular}

Table-1: Various characteristics of patients

\begin{tabular}{|c|c|c|c|c|}
\hline \multirow{2}{*}{ Age Groups } & \multicolumn{2}{|c|}{ Sputum Eosinophilia } & & \multirow{3}{*}{ P Value } \\
\cline { 2 - 4 } & Yes & No & Total & \\
\hline Young Age & 1 & 14 & 15 & \\
(18-35 years) & $(0.8 \%)$ & $(11.2 \%)$ & $(12.0 \%)$ & \\
\hline Middle Aged & 30 & 65 & 95 & \\
(36-50 years) & $(24.0 \%)$ & $(52.0 \%)$ & $(76.0 \%)$ & \multirow{2}{*}{0.024} \\
\hline $\begin{array}{c}\text { Old Aged } \\
\text { (51-80 years) }\end{array}$ & $\begin{array}{c}1 \\
(0.8 \%)\end{array}$ & $\begin{array}{c}14 \\
(11.2 \%)\end{array}$ & $\begin{array}{c}15 \\
(12.0 \%)\end{array}$ & \\
\hline Total & 32 & 93 & 125 & \\
& $(25.6 \%)$ & $(74.4 \%)$ & $(100 \%)$ & \\
\hline
\end{tabular}

Table-2: Showing Association of Age and Sputum Eosinophilia 


\section{DISCUSSION}

Asthma is a complex respiratory tract disease and involves hyper-responsive airways and obstruction in the airflow of variable intensity. According to World Health Organization data more than 339 million people had asthma worldwide in $2016 .{ }^{13}$ It is labeled as a type 1 hypersensitivity reaction. Previous literature has shown that there are several methods that can assess inflammation in the airways. It is proposed that methods that are noninvasive have a high safety profile, are easy to use, and are convenient for patient's surveillance, particularly in those who have severe asthma. The current study revealed that serum IgE levels and peripheral eosinophil counts were raised significantly in patients with severe persistent asthma in comparison to sputum eosinophilia. Factors such as age, gender, and duration of symptoms were assessed for having any association with these inflammatory markers, and only one association was seen, i.e., between sputum eosinophils and age; however, no other association was present.

In a longitudinal study conducted by Ankan Bandyopadhyay in 2013, a relationship between change in the sputum eosinophil count and forced expiratory volume in one second (FEV1) in response to treatment of bronchial asthma patients was observed. The authors also studied the outcome of the treatment of asthmatic patients and predicted prognosis from baseline sputum eosinophil count. The results showed that to achieve adequate improvement in FEV1 in asthmatic patients, a long time was required when sputum eosinophils were $\geq 3 \%{ }^{14}$ Negative correlations were found between FEV1 \% predicted and sputum eosinophil count. The authors concluded that sputum eosinophil count is an excellent biomarker of airway inflammation and can serve as a valuable biomarker to evaluate the severity of the disease, treatment outcome, and asthma prognosis. The current study also concluded the same ${ }^{14}$.

I Davila et al. in 2015 studied the relationship between serum total $\mathrm{IgE}$ and disease severity in patients with allergic asthma in the Spanish population. They also explored the main predictors of IgE levels and found that levels of total serum IgE varied markedly. ${ }^{15}$ There was no association between FEV1 or asthma severity. The patients who had severe asthma had a higher percentage of serum $\mathrm{IgE}$ levels ${ }^{15}$. The current study results were similar. Davila et al. concluded that predictors of higher $\operatorname{IgE}$ were young age, sensitization to more than two allergens, male gender, and having a family history of asthma. Two of these predictors, i.e., age and gender, were assessed in the current study, and it was found that only age had a significant association with sputum eosinophilia, but it didn't have any association with raised $\operatorname{IgE}$ levels or peripheral eosinophilia, and also the gender had no association. Another study conducted by Akihiko Tanaka et al. in 2014 studied an association between change in total IgE levels and asthma control retrospectively. They assessed associations between longitudinal change in $\operatorname{IgE}$ and clinical characteristics, including asthma control, asthma control test score, allergenspecific IgE, pulmonary function test. They noticed that patients with higher levels of $\operatorname{IgE}$ had higher mean age, more asthma exacerbations in a year, lower asthma control test scores, and were using corticosteroids more often. Uncontrolled asthma and aspergillus specific $\operatorname{IgE}$ was frequently seen in patients with high IgE levels. They concluded that both poor asthma control and aspergillus specific $\operatorname{IgE}$ were associated with raised $\operatorname{IgE}^{16}$. No such factors were studied in the current study, so comment on the association cannot be made.

A cross-sectional study by Roshan M. Kumar in 2017 evaluated the correlation of serum IgE, sputum eosinophilia, and blood eosinophil count with clinical asthma severity. The results displayed an inverse correlation between serum IgE levels and sputum eosinophil count with forced expiratory volume 1 (FEV1). It was found that sputum eosinophilia was significantly present in patients with severe asthma. A significant association was found between IgE, sputum eosinophilia, and peripheral eosinophils with severe persistent asthma ${ }^{12}$. The current study also showed a high frequency of these three in patients with severe asthma.

\section{CONCLUSION}

Inflammatory markers like serum Ig E level and blood eosinophil count are raised in patients with severe persistent asthma. These inflammatory markers can be used conveniently along with other tools for establishing the diagnosis, monitoring treatment response, and yielding a view about prognosis in patients with severe persistent asthma.

\section{Limitations:}

Our study had some limitations: It was a crosssectional study, so the results cannot be generalized, only patients with severe asthma were assessed, so the frequency of inflammatory markers in mild and moderate asthma couldn't be determined, patients with higher IgE were not assessed for allergic 
aspergillosis, and patients with eosinophilia were not assessed for parasitic infections.

\section{REFERENCES}

1. Grant EN, Wagner R, Weiss KB: Observations on emerging patterns of asthma in our society. $\mathrm{J}$ Allergy ClinImmunol 104(2 Pt 2): S1-S9, 1999.

2. 2012 National Health Interview Survey as compiled by the centers for disease control and prevention on $3 / 5 / 2014$ and posted at http://www.cdc.gov/asthma/nihs/2012table41.htm.

3. Sara Waqar Khan, Ali Hamid, Fuad Ahmad Siddiqi, Mehroo Bakhtawar. Frequency of allergic asthma and common aeroallergens sensitization in Pakistani patients of bronchial asthma. JPak Med Assoc. 2018; 68(8):1217-21.

4. Global Health Estimates 2016: Disease burden by Cause, Age, Sex, by Country and by Region, 2000-2016. Geneva, World Health Organization; 2018.

5. Lugogo N, G.Que L, L.Gilstrap D, Kraft M. Asthma: Clinical Diagnosis and Management. In Murray J.F, Nadel J. Text Book of Respiratory Medicine. Sixth ed. Canada Elsevier Saunders publisher; 2016; p.731.

6. Simpson JL, Scott R, Boyle MJ, Gibson PG (2006) inflammatory subtypes in asthma: assessment and identification using induced sputum. Respirology 11: 54-61.

7. Haldar P, Pavord ID: Non-eosinophilic asthma: a distinct clinical and pathologic phenotype. J Allergy ClinImmunol 119(5):1043-1052, quiz 53-4, 2007.

8. Hastie AT, Moore WC, Meyers DA, et al.: Analyses of asthma severity phenotypes and inflammatory proteins in subjects stratified by sputum granulocytes. J Allergy Clin Immunol. 125(5):1028-1036.e13,2010.

9. Porsbjerg C, Lund TK, Pederson L, et al.: Inflammatory subtypes in asthma are related to airway hyper responsiveness to mannitol and exhaled NO. J Asthma 46(6):606-612, 2009.

10. Global Initiative for Asthma (GINA), National Heart, Lung and Blood Institute (NHLBI) Global Strategy for Asthma Management and Prevention. Bethesda (MD): Global Initiative for Asthma (GINA), National Heart, Lung and Blood Institute (NHLBI); 2006. p. 339. Available from: http://www.ginasthma.com. [Last accessed on $2014 \mathrm{Jul}$ 17].

11. National Heart, Lung, and Blood Institute. Guidelines for the Diagnosis and Management of Asthma NIH Publication No. 97-4051A. Bethesda,MD:National Institutes of Health;1997

12. Kumar RM, Pajanivel R, Koteeswaran G, Menon SK, Charles PM. Correlation of total serum immunoglobulin E level, sputum, and peripheral eosinophil count in assessing the clinical severity in bronchial asthma. Lung India. 2017; 34(3):256-61.

13. Global, regional, and national incidence, prevalence, and years lived with disability for 328 diseases and injuries for 195 countries, 1990-2016: a systematic analysis for the Global Burden of Disease Study 2016. Lancet 2017; 390: 1211-59.

14. Bandyopadhyay A, Roy PP, Saha K, Chakraborty S, Jash D, Saha D. Usefulness of induced sputum eosinophil count to assess severity and treatment outcome in asthma patients. Lung India: official organ of Indian chest society. 2013 Apr; 30(2):117.

15. Davila I, Valero A, Entrenas LM, Valveny N, Herráez L. Relationship between total serum $\operatorname{IgE}$ and severity of disease in patients with allergic asthma in Spain. Journal of investigational allergology \& clinical immunology. 2015; 25(2):120-7.

16. Tanaka, A., Jinno, M., Hirai, K. et al. Longitudinal increase in total IgE levels in patients with adult asthma: an association with poor asthma control. Respir Res 15, 144 (2014).

\section{The Authors:}

Dr. Shanawer Qaiser

Registrar,

Department of Pulmonology,

Shaikh Zayed Medical Complex, Lahore.

Dr. Muhammad Saqib

Assistant Professor,

Department of Pulmonology,

Shaikh Zayed Medical Complex, Lahore.

Prof. Talha Mahmud

Head, Department of Pulmonology,

Shaikh Zayed Medical Complex, Lahore.

\section{Corresponding Author:}

Dr. Muhammad Saqib

Assistant Professor,

Department of Pulmonology,

Shaikh Zayed Medical Complex, Lahore.

Email:dr.saqib.ch@gmail.com 